\title{
A conceptual framework for prioritization of invasive alien species for management according to their impact
}

\author{
Sabrina Kumschick', Sven Bacher², Wayne Dawson³, Jaakko Heikkilä4, \\ Agnieszka Sendek ${ }^{5}$, Therese Pluess², Tamara B. Robinson', Ingolf Kühn ${ }^{5}$
}

I Centre for Invasion Biology, Department of Botany and Zoology, Stellenbosch University, Matieland, 7602, South Africa 2 University of Fribourg, Department of Biology, Ecology \& Evolution Unit, Ch. du Musée 10, 1700 Fribourg, Switzerland 3 Ecology, Department of Biology, Universitätsstrasse 10, Konstanz, D 78464, Germany 4 MTT Agrifood Research Finland, Economic Research, Latokartanonkaari 9, 00790 Helsinki, Finland 5 UFZ, Helmholtz Centre for Environmental Research - UFZ, Dept. Community Ecology, Theodor-Lieser-Str. 4, 06120 Halle, Germany

Corresponding author: Sabrina Kumschick (sabrina.kumschick@alumni.unibe.ch)

Academic editor: U. Starfinger| Received 7 December 2012 | Accepted 11 December 2012 | Published 14 December 2012

Citation: Kumschick S, Bacher S, Dawson W, Heikkilä J, Sendek A, Pluess T, Robinson TB, Kühn I (2012) A conceptual framework for prioritization of invasive alien species for management according to their impact. NeoBiota 15: 69-100. doi: $10.3897 /$ neobiota. 15.3323

\begin{abstract}
The number of invasive alien species is increasing and so are the impacts these species cause to the environment and economies. Nevertheless, resources for management are limited, which makes prioritization unavoidable. We present a prioritization framework which can be useful for decision makers as it includes both a scientific impact assessment and the evaluation of impact importance by affected stakeholders. The framework is divided into five steps, namely 1) stakeholder selection and weighting of stakeholder importance by the decision maker, 2) factual description and scoring of changes by scientists, 3) evaluation of the importance of impact categories by stakeholders, 4) calculation of weighted impact categories and 5) calculation of final impact score and decision making. The framework could be used at different scales and by different authorities. Furthermore, it would make the decision making process transparent and retraceable for all stakeholders and the general public.
\end{abstract}

\section{Keywords}

stakeholder, decision maker, exotic, generic scoring system, impact, value

Copyright Sabrina Kumschick et al. This is an open access article distributed under the terms of the Creative Commons Attribution License 3.0 (CC-BY), which permits unrestricted use, distribution, and reproduction in any medium, provided the original author and source are credited. 


\section{Introduction}

Impacts of invasive alien species (IAS) affect different receptor environments, and are often divided into environmental and socio-economic impacts. Some of these impacts can result in substantial monetary costs and/or alterations to entire ecosystems and social systems (O'Dowd et al. 2003, Pimentel et al. 2005, Reaser et al. 2007, Vilà et al. 2010). At an international level the ecological impacts of IAS are addressed by the Convention on Biological Diversity (CBD 1992). Through this convention the need for prioritization and management of priority species has been highlighted in the Strategic Plan for Biodiversity 2011-2020 (COP 10 2010), although no guidance on how to achieve this ideal is provided.

There has been recognition that societies need to mitigate negative impacts of IAS, i.e. find appropriate means to manage IAS in a way that their impacts are at least minimized, e.g. by eradication, reduction below a specific threshold, or containment. However, resources to manage IAS are limited and with increasing globalization, the influx of potentially harmful organisms will likely continue to increase (Perrings et al. 2010, Essl et al. 2011). There are two approaches to this problem. Firstly, to limit new alien species from entering an area/country, for which purpose border control risk assessments have been developed (e.g., Pheloung et al. 1999, Bomford 2008, see Hulme 2012 and Leung et al. 2012 for reviews). Secondly, alien species that escape border controls (Bacon et al. 2012) or have never been subjected to border control risk assessment, and which cause high impact must be managed in their new ranges (see above). Hence, a system is needed that facilitates the optimal allocation of limited resources to manage those IAS that are most harmful in a given area. Such a system would ideally integrate the severity of effects on the environment, as well as on the economy and the society in question, allowing decision makers to prioritize certain high impact species for management. However, also cost-effectiveness of management needs to be taken into account.

Alien species, however, do not have only negative effects. The majority of the alien plants in Europe were deliberately introduced, e.g. as ornamental, horticultural, restoration, agricultural or forestry species (Hopper 2007, Lambdon et al. 2008, Pyšek et al. 2009) with their respective social, economic and environmental benefits. Management of such species, which are detrimental in some aspects (e.g. for biodiversity) and beneficial in others (e.g. forestry), can result in conflicts among involved stakeholders. For example, the introduction to South Africa of alien Acacia species which subsequently became invasive had differential effects on local communities. On the one hand, communities suffered from water scarcity due to increased evapotranspiration by the acacias. On the other hand, they benefitted from fuel wood and building timber (De Wit et al. 2001). Such situations have led to the recognition of a need for a framework to document the different consequences of an IAS for different groups of stakeholders (Stoll-Kleemann and Welp 2006, Binimelis et al. 2007, Kapler et al. 2012) and recently a few attempts have been made to develop applications which incorporate 
stakeholders (Cook and Proctor 2007, Hurley et al. 2010, Liu et al. 2011, De Lange et al. 2012, Forsyth et al. 2012).

Parker et al. (1999) developed a framework to assess the ecological effect of IAS, arguing that the total effect of an invader includes three fundamental dimensions: range, abundance, and the per-capita or per-biomass effect of the invader, i.e. the magnitude of ecological change it causes. Since then progress has been made in scoring the overall negative effects of alien species (e.g., Nentwig et al. 2010, Kumschick and Nentwig 2010, Pluess 2011). A very detailed assessment scheme for impacts of genetically modified organisms was presented by Kowarik et al. (2008) which can easily be adapted for invasive species. However, few of these impact scoring approaches explicitly addressed potentially competing interests of stakeholders (i.e. various ecological, economic or social interests) within the context of management of IAS. Furthermore, these studies ignore potential positive effects of IAS, which might be crucial for some species and stakeholders (see e.g., Schlaepfer et al. 2011 for a review). These points are important because biological invasions represent a complex societal issue for two reasons. First, the scientific knowledge about biological invasions and the outcome of different management options are highly uncertain and second, both conflicts of interests and values are prominent in a problem-solving context such as the management of IAS (Kueffer and Hadorn 2008). Thus, as in any environmental decision making process, IAS management has to minimize conflicts characterized by ecological, economic and social value judgments of different stakeholders (Liu et al. 2010, 2011). Furthermore, if all types of impacts of IAS are to be assessed (i.e. ecological and socio-economic impacts), then the different scientific disciplines and associated value systems require a common currency with which to measure impact. Another layer of complexity is added by the fact that different sections of administration and stakeholder groups with differing agendas need to be integrated, since plants, animals and human health are in the responsibility of different agencies and/or ministries (e.g., IPPC International Plant Protection Convention, OIE - World Organization for Animal Health, WHO - World Health Organization).

At present, several studies have proposed prioritization methods for the management of weeds (e.g., Skinner et al. 2000, Virtue et al. 2001, Robertson et al. 2003, Tassin et al. 2006, Randall et al. 2008, Brunel et al. 2010). However, only few schemes considered potential conflicts of interest when evaluating which weed species to prioritize for control first, mainly in South Africa (Robertson et al. 2003, Forsyth et al. 2012, De Lange et al. 2012). Other studies that specifically tackled the complexities of conflicting interests and values in IAS management have usually focused on particular outbreak situations of a single species (Maguire 2004, Liu et al. 2010, 2012). Based on a participatory approach in Western Australia, the prioritization by an assessment committee differed from current resource allocations in Western Australia (Cook and Proctor 2007). A similar approach was taken by Roura-Pascual et al. (2010) for South Africa. However, such a potentially time-consuming and re- 
source-demanding approach might not always be possible. Hence, decision makers and especially governmental bodies are still in need of a generic decision making aid that facilitates the identification of priority species whilst minimizing or reconciling potential conflicts of interest.

The basic problem with many of the systems to date is a fundamental one. Decisions made for IAS management are heavily influenced by judgements which are predominantly based on inputs from scientists (Wilhere 2008). In general, the role undertaken by scientists in decision making falls along a gradient (Lach et al. 2003). At one end of the continuum, scientists may simply report results that others use to make decisions. Alternatively, they may interpret these results and work with decision makers to integrate these results into the decision making process. At the other end of the continuum, scientists may be actively involved in decision making by advocating for a specific decision or in the extreme, making the decision themselves. While traditionally scientists largely shied away from active involvement in decision making (Lach et al. 2003), recent years have seen increasing advocacy (Marris 2006, Scott et al. 2007). This has resulted in a call for science inputs into decision making to be supportive of the process but dispassionate towards policy outcomes (Lackey 2007), recognising that science is but one vital element that needs to be considered in decision making. Against this background we argue that the process of objectively describing with scientific methods changes associated with an IAS has to be explicitly separated from the proximate subjective societal evaluation of impact, which is based on values. For the actual decision making for management, however, facts (effects on environment and socio-economy) need to be connected to values (judgement of involved stakeholders).

Here, we propose a comprehensive framework which aims to explicitly separate the scientific description of changes caused by IAS from the value systems of affected stakeholders who may have differing interests. Furthermore, it addresses both negative and positive effects of IAS, since positive effects are often neglected in purely ecological impact studies (Goodenough 2010, Davis et al. 2011, but see Pyšek et al. 2012 for a global review).

\section{Framework for impact evaluation of IAS}

The framework suggested here is divided into five steps. The different steps are shortly introduced in this section. We then present more details about the scorings and values in the following sections and in Figures 1 and 2.

Step 1: Stakeholder selection and weighting of stakeholder importance. A call for stakeholder participation is launched and they are encouraged to claim their interest. The stakeholder group is formed such that it is sufficiently representative and 


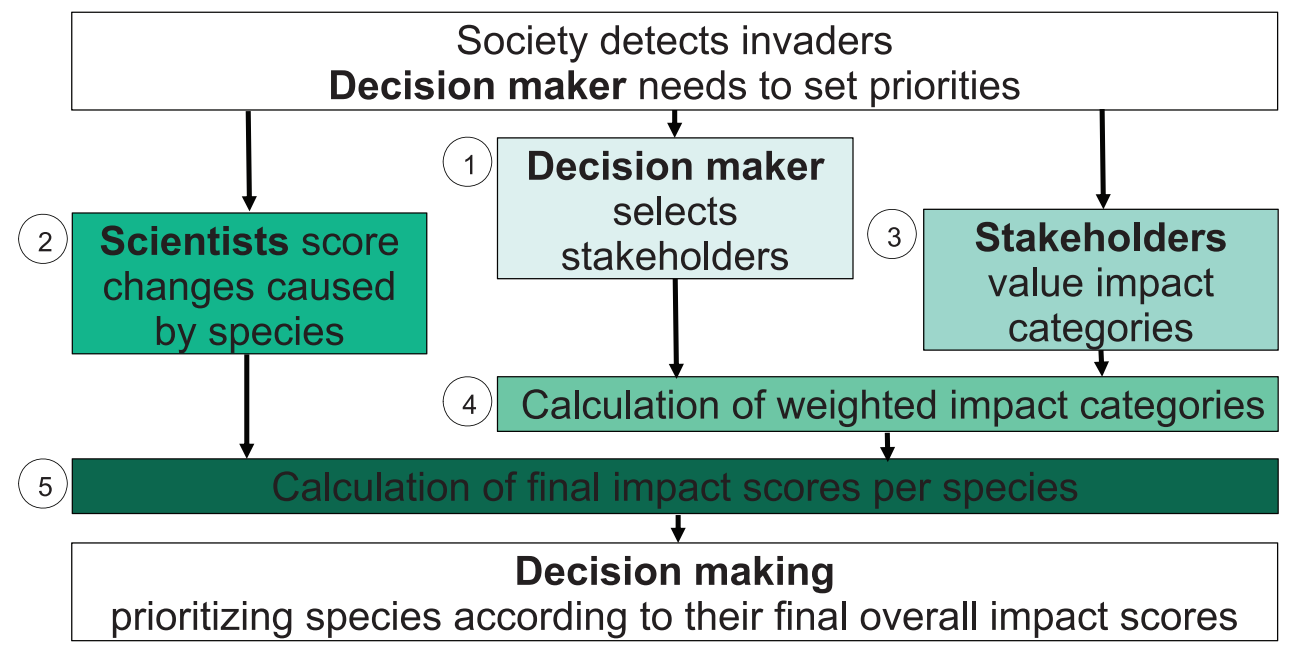

Figure I. Schematic overview of the conceptual framework to assess change in different impact categories for each species, capture stakeholders' interests and weigh stakeholders and calculate a final impact score for each species, see chapter "framework for impact evaluation" of IAS for a brief and the following chapters for detailed explanation.

appropriate for the task at hand. The participating stakeholders are then categorized according to their importance in relation to the issue that is being evaluated. This process produces Stakeholder Weights (SW), and should be conducted in a transparent and logical way.

Step 2: Description and scoring of changes due to IAS. For this step we propose a scoring system, based on two main impact classes (ecological, socio-economic) each with several categories (e.g., agriculture, health, infrastructure, herbivory, hybridization). Negative and positive changes are separately evaluated for each IAS. The outcome of this step is hereafter referred to as Change Assessment Score (CAS).

Step 3: Valuing the relative importance of impact categories by stakeholders. After identifying affected stakeholders in step 1, each stakeholder values the relative importance of all impact categories. Negative and positive categories are valued separately. When valuing the categories, the stakeholders do not know the species assessed in step 2 and their change assessment scores. This is called Stakeholder Value Assessment (SVA).

After selection of stakeholders (step 1), the description of changes (step 2) and the assessment of stakeholder weights (step 3) can be conducted at the same time as one does not depend on the outcome of the other. The following steps in turn can only be performed if the outcomes of the former steps are known. 

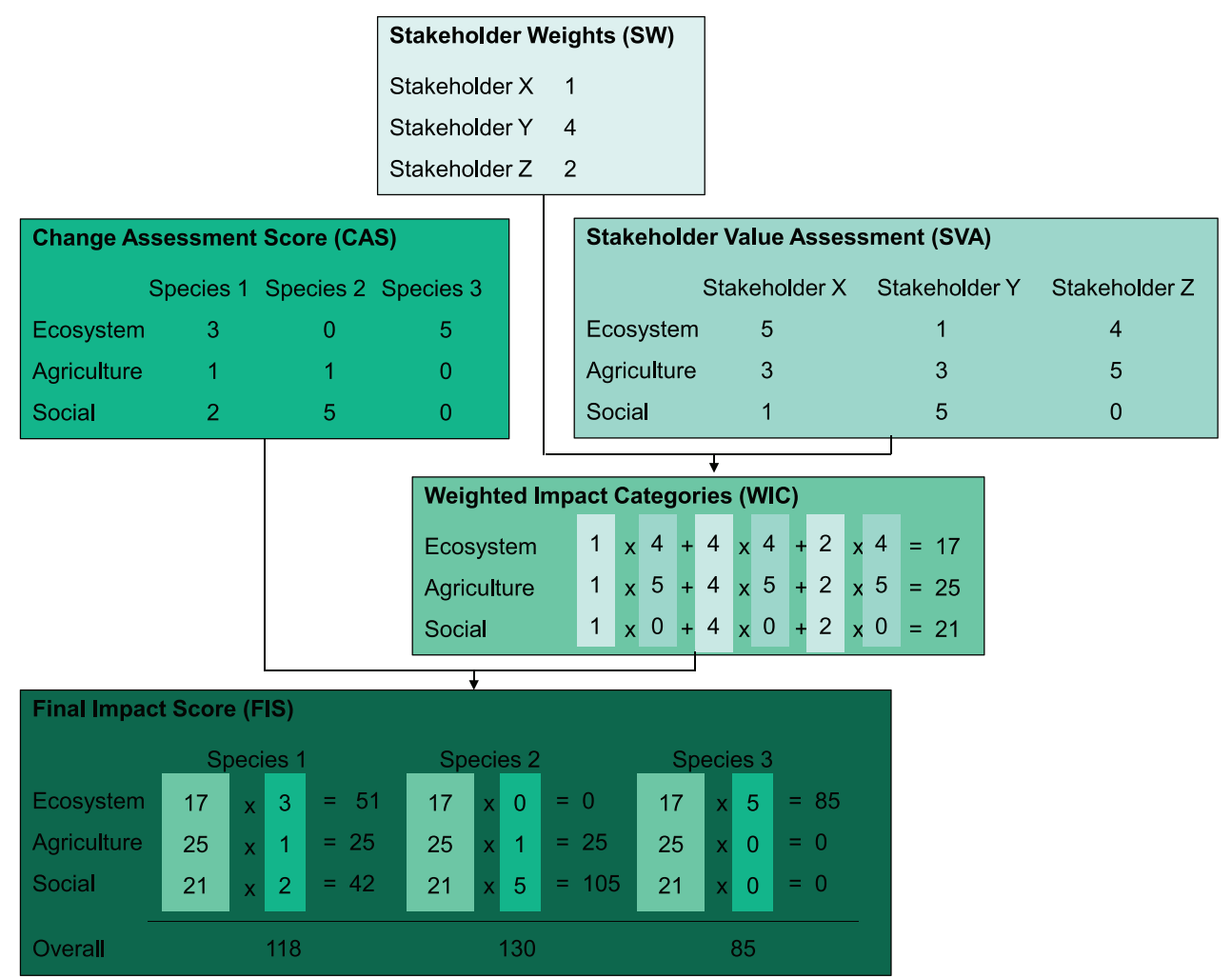

Figure 2. Fictitious example on how to calculate the different values of the prioritization framework. For brevity, we limit the number of categories from the scientific impact assessment in Step 2 of the framework to 3 (out of 24). Species 2 has the highest social Change Assessment Score (CAS), whilst species 3 has the highest CAS for ecosystem changes. The decision maker gives stakeholder $Y$ the greatest weighting. In the Stakeholder Value Assessment (SVA), stakeholder X gives the greatest value to ecosystem, whilst $\mathrm{Y}$ values the social category the highest, and stakeholder $\mathrm{Z}$ values agriculture most. Multiplying these values by the stakeholder weights and summing the products gives Weighted Impact Categories (WIC), and multiplying these values by respective category CAS values gives the final overall impact scores per species. Note that WIC values for positive change need to be inversed to negative values upon calculation of final impact scores per category and overall.

Step 4: Calculating weighted impact categories. This is done by combining the outcomes of step 1 and step 3, which produces Weighted Impact Categories (WIC).

Step 5: Final impact scores. The Final Impact Scores (FIS) for each species are calculated by combining the CAS (step 2) with WIC (step 4).

In the following sections, the five steps are described in detail, and in the final part of the paper the usefulness of the scheme for different potential end-users and advantages and potential shortcomings are discussed. 
Table I. Prioritizing scheme in five steps, describing the action taken at each step, identifying the actor of each step and defining the output of each step. ${ }^{*}$ ) can be performed simultaneously.

\begin{tabular}{c|l|c|c}
\hline Step & \multicolumn{1}{|c|}{ Action } & Actor & Output \\
\hline 1$)$ & $\begin{array}{l}\text { Decision maker chooses the stakeholders and } \\
\text { decides on the form and execution of the } \\
\text { weighting process }\end{array}$ & Decision maker & $\begin{array}{c}\text { SW = Stakeholder } \\
\text { Weights }\end{array}$ \\
\hline $\left.2^{*}\right)$ & $\begin{array}{l}\text { Assessment of change: the change a species incurs } \\
\text { for each category from App. A is scored }\end{array}$ & Scientists & $\begin{array}{c}\text { CAS = Change } \\
\text { Assessment Score }\end{array}$ \\
\hline $\left.3^{*}\right)$ & $\begin{array}{l}\text { Stakeholders value each category from App. A, } \\
\text { regardless of the species and change a species } \\
\text { incurred }\end{array}$ & Stakeholders & $\begin{array}{l}\text { SVA = Stakeholder } \\
\text { Value Assessment }\end{array}$ \\
\hline 4$)$ & $\begin{array}{l}\text { Calculation of weighted impacts by combining } \\
\text { SVA } \times \text { SW }\end{array}$ & $\begin{array}{c}\text { Decision maker }(\text { or } \\
\text { scientists or consultant })\end{array}$ & $\begin{array}{l}\text { WIC = Weighted } \\
\text { Impact Categories }\end{array}$ \\
\hline 5$)$ & $\begin{array}{l}\text { Calculation of final impact score } \\
\text { WIC } \times \text { CAS }\end{array}$ & $\begin{array}{c}\text { Decision maker }(\text { or } \\
\text { scientists or consultant })\end{array}$ & $\begin{array}{c}\text { FIS = Final Impact } \\
\text { Score }\end{array}$ \\
\hline
\end{tabular}

\section{Step I: Stakeholder selection and weighting of stakeholder importance}

Stakeholders play a central role in the presented scheme, as their opinions are crucial for evaluating the subjective impact categories through formal and structured analysis. The stakeholder process needs to be carefully planned, structured and conducted, accounting for the aim and needs of the problem at hand (Renn and Schweizer 2009). There are three main things to consider: a) who should participate; $b$ ) what is the form of the participatory process; and c) whose opinion counts.

\section{Who should participate?}

A stakeholder is - put simply - someone who can affect or is affected by the issue at stake (Freeman 1984, cited in Mitchell et al. 1997). There are several methods available that one could use to come up with a list of stakeholders (see, e.g. Pretty 1995, Reed et al. 2009). For instance, an often-applied method is the so called 'snowball technique' which involves consulting every stakeholder as long as no new actors are indicated. How representative the stakeholder group should be depends on the aim of the process (e.g. Rowe and Frewer 2005, Webler and Tuler 2006, Reed 2008, Renn and Schweizer 2009, Wesselink et al. 2011). For instance, the aim of the stakeholder process may be to avoid missing information and perspectives, to try to find win-win situations or compensations from winners to losers, to represent and discuss all relevant arguments, to ensure that less-privileged groups are given the opportunity to have their voices heard, or to enlighten policy processes by illustrating the diversity of claims, opinions and values (Renn and Schweizer 2009). We suggest that at least all those who are potentially affected by the species should have a possibility to participate or have their voice heard through some other participant (e.g. an organization). In practice, stakeholders would consist of, for instance, agricultural and silvicultural producers, environmental organizations, tourist industry, city/town representatives, different outdoor associations (e.g. hunters, bird-watchers, recreationists), and so forth. 


\section{What is the form of the participatory process?}

One main issue regarding the stakeholder process is the form of opinion-forming: is the process aiming at a consensus through deliberation, or are the stakeholders just asked for their individual opinion? If a consensus is sought for, the result of the process in our case would be a single set of weights (see step 3) that could directly be used to weigh the species impacts (resulting from step 2). If each stakeholder is allowed to have their own weights, then these need to be aggregated in some way unless the analysis is to be conducted separately for each stakeholder. A simple way is to average all the weights, in which case each stakeholders' opinion is valued equally. However, if the decision maker wishes to weigh the stakeholder opinions, specific weights for each stakeholder need to be produced.

\section{Whose opinion counts?}

There are both ethical and pragmatic reasons why the decision maker should attend more closely to some stakeholders than others (Colfer et al. 1999). These include fair treatment of those who are more affected by the decision, and that some stakeholders just have a greater likelihood than others of affecting (and being affected by) the issue at stake. There are theories that attempt to explain, often in business context, which stakeholders are being paid more attention to (Reed et al. 2009). One such theory is the theory of stakeholder salience (Mitchell et al. 1997), according to which stakeholders can be categorized using three attributes: power (to affect the decision maker), legitimacy (to the issue at stake), and urgency (of their claims). The more of these three properties a stakeholder has, the higher is their salience and hence their importance in the eyes of the decision maker.

Categorization provides the decision maker with the possibility to influence the prioritization procedure by weighting each of the participating stakeholders. As this may be considered as a source of bias, it should be transparent and ideally based on objective and reliable analysis of stakeholders' attributes (Mark and Shotland 1985, Mushove and Vogel 2005). For instance, Colfer et al. (1999) suggest seven criteria by which to define the most important stakeholders in the case of forest management, score them at a scale 1-3 for each criterion and obtain a weight for each stakeholder by averaging over the criteria. Alternatively there exist for instance pairwise comparison methods (Grafakos et al. 2010) that may be used to produce the required weights.

Weighting is not a straightforward process, especially when numerous attributes of the stakeholders are taken into consideration, and when stakeholders' external environment and interactions are complex (de Reynier et al. 2010, Aaltonen 2011). The decision maker undertaking the categorization ("top-down approach") is by no means the only way of attributing a weight to stakeholders. There are also methods through which the stakeholders themselves come up with a ranking order of their importance (see, for instance, Pretty 1995, Mitchell et al. 1997, Reed 2008, Reed et al. 2009). 
Reed (2008) provides best practices for the stakeholder process, including for instance emphasis on empowerment and equity, representation and analysis of relevant stakeholders, need for clear objectives for the process, choosing methods depending on the context, and integration of scientific and local knowledge. Our framework requires the evaluation and categorization of stakeholder importance. However, as to what the precise format of the stakeholder process should be, we do not specify here for reasons of space. Practical examples in the context of invasive alien species can be found in Cook and Proctor (2007), Hurley et al. (2010), Skurka Darin et al. (2011) and De Lange et al. (2012). The desired outcome nonetheless is clear: the process should produce a set of weights for the different impact categories that would broadly reflect the values present in the society.

\section{Step 2: Description and scoring of changes}

The second step of the decision making process aims at recording all changes an IAS causes in the introduced range. An impact or change in this case is defined as any deviation from the state of a system before the invasion happened. In order to make comparison between species, different locations and different measurements of impact, we suggest the use of a generic scoring system (e.g., Nentwig et al. 2010, Kumschick and Nentwig 2010). Nevertheless, scoring systems and other prioritization tools suggested so far often only focus on unwanted changes and rarely take into account possible welcome changes which might result from species introductions, as e.g. increasing population densities of threatened native species (Schlaepfer et al. 2011) or economic benefits (Leung et al. 2012). For a balanced view, however, positive effects should no longer be neglected or even ignored, as many stakeholders profit from such IAS. When a decision is needed on how to deal with an IAS, all possible stakeholder interests need to be accounted for to ensure wide acceptance and support for the decision (Myers et al. 2000, Gardener et al. 2010; see step 1 for more details). However, whether changes are perceived as "positive" or "negative" depends on the value system of the stakeholders concerned (Simberloff et al. 2012). For example, the invasion of the weed Paterson's Curse (Echium plantagineum) in Australia was perceived as detrimental by ranchers because the plant is toxic to livestock, but beekeepers profited from its proliferous honey production (Harris 1988). In the following description of impact (changes), we continue to use the terms "positive" and "negative", but aim to define them in an objective, value-free way by describing the direction of change relative to pre-invasion state of the system.

Based on previously published scoring systems (e.g., Nentwig et al. 2010, Kumschick and Nentwig 2010, Kumschick et al. 2011, Pluess 2011, Kumschick et al. 2012), we determined a wide range of changes IAS could cause in the introduced area (Appendix A). The scoring system consists of two main classes of changes, socioeconomic and environmental, and each class has 6 categories. The categories for environmental changes are hybridization, competition, transmission of diseases to wild- 
life, herbivory/toxicity, predation, and ecosystem effects in general. Changes to the environment can be negative or positive. Changes in the negative direction denote a decrease in an attribute of ecosystem function or native biodiversity compared to the state before the IAS was introduced and can range from no changes to the environment (score 0 ) to the maximum reduction possible (score 5). Positive effects can occur in systems previously altered by human-induced disturbance, e.g. alien species, land-use change, pollutants, eutrophication etc., but where an invader can fulfil some or many of the functions that previously existed or were fulfilled by species before perturbation. Thus, these scores can also range from very low changes $($ score +1$)$ to the complete restoration of an expected, pre-invasion state of system functioning (score +5 ). Furthermore, positive effects can occur if an invasive species enhances a function still provided by other resident species. Please note that "positive" and "negative" do not denote human values, but relate to the direction of environmental change after invasion relative to the pre-invasion state of the system: "positive" indicates changes towards the pre-invasion state, "negative" changes away from the pre-invasion state. Because a species might simultaneously cause positive and negative changes within the same category, but through different mechanisms (see e.g. the Echium example from Australia described above), we score these positive and negative changes separately. Furthermore, it is possible that a stakeholder values positive and negative changes differently, so by keeping them separate, the categories might also be weighted differently.

The socio-economic categories are changes to human health, infrastructure, animal production, agriculture, forestry and human social life. Socio-economic changes can also be negative or positive, depending on whether they decrease or increase human well-being. Negative changes often consist of direct monetary or utility losses and can range from no changes (score 0 ) to the maximum negative change possible (score 5). Positive effects are also possible, for example, more possibilities for hunting an invasive species whilst alleviating hunting pressure on native mammals, or provision of a nectar source for important pollinators of agricultural crops. These effects can also range from very low $($ score +1$)$ to the highest positive effects possible $($ score +5$)$. Again, we have positive and negative changes within the same category, but we score these separately because they might occur through different mechanisms.

Not all changes are equally relevant for different taxa. For example, the difference in changes between alien plants and animals is likely to be quite marked in some cases. Therefore, we propose not to use the scores of change ("impact" scores) as measurement themselves, but to calculate the percentage score achieved out of the maximum possible for a given species. Hence if plants and animals are to be assessed in the same prioritization round, then for questions which are not relevant for plants or animals respectively (e.g. ecological impact through predation for plants), the overall-score should be adjusted by calculating the percentage score achieved out of the maximum attainable score for the species, and then multiplying by the maximum score attainable among all species considered. The critical point here is that in any round of prioritization, each candidate species should have an equal opportunity of attaining the same maximum score possible. 
In many cases, effects of IAS on the recipient environment and economy have not been thoroughly studied. As in the whole invasion process, the uncertainty level of impacts can therefore be high and communicating these uncertainties is crucial in the decision making process (Liu et al. 2011, Leung et al. 2012). We therefore suggest including information about certainty in this step to account for the reliability of the data source used for scoring (low, medium, high). For example, this can be based on the type of data source (e.g. Low: mentioned in paper, no reference, speculation, expert judgement. Medium: evidence in literature, observational. High: demonstrated evidence in peer-reviewed literature, experimental) (Spear and van Wilgen, pers. comm.). This also deals with the fact that an impact score of 0 can be both, "no impact known" and "no impact detectable". Including a certainty level enables to distinguish these possibilities (e.g. Low: no information. Medium: unlikely based on life history, expert judgement, literature observation or speculation that there is no impact. High: demonstrated evidence in peer-reviewed literature, experimental) (Spear and van Wilgen, pers. comm.). These certainty levels are to be communicated to the decision maker and can potentially influence the final decision making. Furthermore, they can identify research needs (e.g., species with large effects with low certainty).

\section{Step 3:Valuing the importance of impact categories by stakeholders}

At this stage, we will leave the domain of objective quantification again and focus on the societal context. Scientific measurements of impact are valued differently by different stakeholders and the valuation may differ in space and time and from case to case (Sagoff 2011). Biological invasions will thus be perceived to have different impacts for different societal sectors and different groups of stakeholders. Several species may be perceived as beneficial e.g. for farming, forestry, hunting or landscape restoration, but as detrimental from a nature conservationists point of view.

The approach we suggest here (as vizualised in Figures 1 and 2) would be to let each stakeholder group give scores to each impact category according to their perceived importance for them. For example, for an impact assessment of alien species in a city, two possible stakeholder groups might be the tourism industry and environmentalists. The tourism industry is likely to assign the highest scores to the positive category on human social life, while environmentalists might give highest priority to the negative categories of change in ecosystems in general and on other species (e.g. through competition). There are a few studies on invasive species that explicitly weight the different assessment criteria (Cook and Proctor 2007, Ou et al. 2008, Hurley et al. 2010, Skurka Darin et al. 2011). The processes by which this is done in these studies are mostly rating or paired comparison (analytical hierarchy process), but also fixed point scoring or the ratio method (Grafakos et al. 2010).

We propose a fixed point scoring method to rank the importance of the categories by giving the stakeholders a fixed amount of points (e.g. 100) to freely distribute among the impact categories. This would reflect their preferences, but it is also good 
to note that if the stakeholders have extreme agendas, they might also end up with extreme point allocations. As mentioned, there are other mechanisms that could alternatively be used, for instance scoring each category at scale 1-5, and possibly also a combination of these. However, whatever the procedure, the stakeholders need to be given clear instructions on what is expected of them.

As indicated in the previous section, negative and positive categories are valued separately. When valuing the categories, the stakeholders do not know the Change Assessment Scores (CAS) of the alien species assigned by scientists in step 2, neither do they know which species are being assessed in order to avoid biased valuation towards certain species. In the same line of argument, stakeholders begin the valuation scoring without knowing the scores or even the participation of other stakeholder groups. If further deliberation in the stakeholder process is desired, it may follow this initial valuation.

\section{Step 4: Calculating weighted impact categories}

For each stakeholder, the values of each impact category are multiplied with the weight score given to this stakeholder by the decision maker. For example, two stakeholders, named $\mathrm{A}$ and $\mathrm{B}$ here, assign 2 and 5 points, respectively to the category "agriculture". The decision maker weights the opinion of stakeholder $A$ as 3 times higher than the opinion of stakeholder B, thus the impact scores of A are multiplied by a factor 3 while those of B remain unchanged (see Figure 2 for another example). The overall weighted impact score for the category "agriculture" would in this example receive a score of $2 \times 3+5 \times 1=11$. This procedure yields weighted impact values for each category, incorporating the value system of all stakeholders and their importance for the decision maker. The highest weighted impact values represent the categories that are valued most across all stakeholders, i.e. those categories in which impacts would have the most serious effects for society.

\section{Step 5: Final impact scores}

The final impact scores for each species are calculated by multiplying the Change Assessment Scores (CAS) for each impact category (step 2, Figure 1) by the Weighted Impact Categories (WIC) over all stakeholders (step 4, Figure 1). This procedure essentially combines the objectively measured impact with an overall valuation of this impact by society. To calculate an overall impact score for a species, all final impact scores are summed. It should be noted here that upon calculation of the weighted impact scores, the sign of the CAS should be inverted to negative values, so that the final summed impact score reflects the net perceived impact of a given species. For example, if a high scoring negative-change species has a high positive-change score in one category, and the major stakeholders rank this positive change highly, then the finally obtained impact score will be reduced by the larger positive weighted impact score. The same procedure is applied for the associated certainty scores. We would therefore also 
learn about the combined certainty attached to the impact scores. Species can then be ranked according to their overall impact scores and/or by the certainty of the scores. Species responsible for large changes in an impact category that is of relatively low value to society are down-weighted, while species scoring low in impact categories that are of high societal value are given more weight (Figure 2). These final overall impact scores are a crucial element in the prioritization of management, amongst others like cost-effectiveness.

\section{Discussion}

Conservation organizations, governments and other interest groups need to prioritize which species to spend limited funds on in order to manage and achieve the best socioeconomic and ecological benefit. Here, we have presented a prioritization system which combines objective ecological information on how species change the state of the invaded environment, with stakeholder assessments evaluating impact categories according to their specific interests and perception of value, to create an overall impact score. Species are thus ranked in importance by combining the overall impact score with an a priori stakeholder rank, according to the perceived importance of stakeholders to the decision maker, who is the ultimate funding body of management measures. The system clearly distinguishes science from values in the decision making process, which is crucial for transparent, rational and sustainable policy making (Wilhere et al. 2012).

By combining stakeholder views and scientific information on species impact, this impact prioritization system can ensure that the outcome of action to manage the most problematic species has little bias from opinions of scientists, or from unintended dominance by any one stakeholder with a loud voice. Ultimately, the decision maker can have some influence on the decision of which species to manage, by deciding which stakeholder group's opinion is the most important. This weighting of importance should be made in a transparent and repeatable way, for example by using the size of the stakeholder group (assuming that larger groups are of greater importance), but other ways of weighting stakeholder importance might be more appropriate, depending on the situation. However, any ranking of stakeholder importance should be done a priori.

For the system to be used in practice, it needs a few more specifications from the side of the user. For example it needs to be specified how to choose and reach the stakeholders, and according to which criteria and by whom they should be weighted. The system is very flexible and easily adaptable in this respect, as well as in relation to the impact scoring scheme that is used. For these and other possible adaptations and specifications, the system should be tested in practice and it should be documented precisely how the steps were performed and which changes were necessary. Generally, the more a system is used in practice, and the higher the awareness of its shortcomings are, the better and more broadly applicable it can become. A good example for this is the Australian weed risk assessment (WRA), which has been tested worldwide and in different ecosystems, and adapted accordingly (Pheloung et al. 1999, Weber et 
al. 2009). For the WRA, it has been tested whether it accurately rejects invaders and accepts harmless, non-invasive species. In the case of the framework suggested here, there is no "right" or "wrong" species to manage in any case since most (if not all) invasive species affect the newly inhabited environment in one or the other way. Naturally, cost-effectiveness of management makes managing some species a more sensible thing to do than other species. Furthermore, because of the subjective influence of the stakeholders in the decision making process, testing the system will not give a definite answer as to whether it would work in practice.

However, we believe the scheme we have presented here is general enough for different types of decision makers/funding bodies to use at different scales, with minimal modifications required. For instance, relatively local invasive species management projects by conservation organizations may only have a small number of species to assess, with few stakeholders involved. The system could just as easily be used at a regional or national level by government bodies. This process would be facilitated by the lists of problematic IAS that already exist in many countries, e.g. Australia's 'Weeds of National Significance' List (Virtue et al. 2001) and list of harmful alien mammals and birds in Europe (Nentwig et al. 2010, Kumschick and Nentwig 2010). This framework could also be of special significance in guiding actions against IAS in developing countries that may lack the policy tools to give action to their national legislation or international obligations.

Another adaptation of the system, should there be a national, multi-species management plan with sufficient funds, would be to split potential species into taxonomic groups (e.g. plants, mammals, birds, invertebrates), or according to habitat/ecosystem (e.g. freshwater or other aquatic habitats, grasslands), which would allow multiple species to be selected for management which are likely to have very different types of impacts in different areas or ecosystems. However, our proposed impact assessment in Appendix A is flexible and broadly applicable enough to allow prioritization for management across a wide range of taxa and ecosystems, if this approach is desired.

Whilst our system can be a useful tool for identifying the highest priority species for management according to society and science, it does not take into account how cost-effective management implementation might be. Ideally, we should try to target those species that are more cost-effective to control or eradicate, at least at local scales. However, the chances of successful control will also depend on other factors than the species itself. Recent studies on the feasibility of eradication found that eradication success mainly depended on the extent of the invaded area (Pluess et al. 2012a) and the habitat type (Pluess et al. 2012b). If the circumstances of the infestation by the top-priority species prohibit effective eradication, then the next species in the list could be chosen. This could also be a useful strategy for picking a single species for management, should several end up with a tied ' $1{ }^{\text {st }}$ place' priority score, and if funds do not allow the management of all. Alternatively the management strategy could switch from a focus on eradication to containment and damage limitation of the top species in sensitive areas. Additionally, management actions can also have potential negative effects on the environment, which can possibly be larger than the effect of the species 
itself. Britton et al. (2011) provide examples on how these risks can be incorporated in management decisions. Furthermore, given legislation and policies cannot be ignored; Governments have certain policy restrictions, for example regarding safety, health issues and nature conservation, which they have to comply with. Therefore, even a species that is not ranked as top priority in the proposed framework might have to be dealt with when it is required by a country's legislation.

This framework could potentially be useful for decision makers who need to set priorities for optimal resource allocation. Possible end-users of the framework besides governmental environmental agencies could also be nature conservation organizations (e.g., WWF), or any other organization interested in assessing the impact of IAS. The framework allows the end-user to set priorities for the management of problematic species across a wide range of taxa, by combining the actual change as described in step 2 (scientific input) and impact valuation in step 3 (stakeholders' valuation of impact categories).

A major strength of the approach highlighted here is the integration of scientific (i.e., objectively measurable) and social (i.e., value-based) assessments of invasive species impacts to prioritize species of concern according to impact severity. In addition, the generic nature of the impact assessment in step 2 and the category valuation by stakeholder makes the system flexible for use on different spatial scales and in different regions.

One potential weakness of the procedure proposed rests at the second step - scientific impact assessment. In practice, information on impacts generally has a high uncertainty and often is based only on expert judgements (Leung et al. 2012). Moreover, betterquantified impacts may be site-specific in their expression and magnitude, making generalization difficult (Virtue et al. 2001). Our scheme could provide an opportunity for targeting more thorough research and assessment of impacts of greatest concern to society, by communicating weighted impact values back to scientists. However, it should be borne in mind that public opinion is fluid, and may not immediately register the less tangible, but potentially detrimental impacts that invasive species can have on society.

Although the framework suggested is primarily meant to prioritize established and invasive species, it could also be used for border control of species which are invasive elsewhere and already known to cause impact, e.g. quarantine species. However, one should be aware of the problems associated with the prediction of future potentially harmful species, and also that this system does not assess entry or establishment probabilities. Particularly early during an invasion, management of species which are still harmless due to their small distributional range but may have a great potential to be detrimental in the future might be more cost-effective than trying to manage widespread species. Understanding how to predict impact is challenging but not impossible, and management decisions have to be made anyway (Leung et al. 2012).

In summary, we have presented a framework for prioritising invazive species according to impact severity, which involves the integration of scientifically assessed impacts per species, and socio-economic valuation of general impact importance across stakeholder groups. In theory, this framework could be implemented at multiple spatial scales, and for any group of species considered for management. However, the real value of the framework is revealed only once it has been thoroughly 
applied and tested, and we encourage the use of this framework to test whether or not it can work in practice as a useful prioritization and decision making tool in invasive species management.

\section{Acknowledgements}

We thank the reviewers for helpful comments on an earlier version of the manuscript, A. Kempel and M. van Kleunen for co-organizing the workshop on "Biological Invasions - Towards general rules across taxa" that initiated this collaboration, and the Inter-University Doctoral Program in Ecology and Evolution, Lausanne for the sponsorship that enabled us to attend.

\section{References}

Aaltonen K (2011) Project stakeholder analysis as an environmental interpretation process. International Journal of Project Management 29: 165-183. doi: 10.1016/j.ijproman.2010.02.001

Bacon SJ, Bacher S, Aebi A (2012) Gaps in border controls are related to quarantine alien insect invasions in Europe. PLoSOne 7(10): e47689. doi: 10.1371/journal.pone.0047689

Binimelis R, Born W, Monterroso I, Rodríguez-Labajos B (2007) Socio-economic impact and assessment of biological invasions. In Nentwig W (Ed.) Biological Invasions. Springer (Berlin/Heidelberg): 331-347. doi: 10.1007/978-3-540-36920-2_19

Boesso G, Kumar, K (2009) Stakeholder prioritization and reporting: Evidence from Italy and the US. Accounting Forum 33: 162-175 doi: 10.1016/j.accfor.2008.07.010

Bomford M (2008) Risk assessment models for establishment of exotic vertebrates in Australia and New Zealand. Invasive Animals Cooperative Research Centre (Canberra).

Born W, Rauschmayer F, Brauer, I (2005) Economic evaluation of biological invasions - a survey. Ecological Economics 55: 321-336. doi: 10.1016/j.ecolecon.2005.08.014

Britton JR, Copp GH, Brazier M, Davies GD (2011) A modular assessment tool for managing introduced fishes according to risk of species and their populations, and impacts of management actions. Biological Invasions 13: 2847-2860. doi: 10.1007/s10530-011-9967-0

Brunel S, Branquart E, Fried G, van Valkenburg J, Brundu G, Starfinger U, Buholzer S, Uludag A, Joseffson M \& Baker R (2010) The EPPO prioritization process for invasive alien plants. Bulletin OEPP/EPPO Bulletin 40: 407-422.

Bryson JM, Patton MQ, Bowman RA (2011) Working with evaluation stakeholders: A rationale, step-wise approach and toolkit. Evaluation and Program Planning 34: 1-12. doi: 10.1016/j.evalprogplan.2010.07.001

Céspedes-Lorente J, de Burgos-Jiménez J, Álvarez-Gil MJ (2003) Stakeholders' environmental influence. An empirical analysis in the Spanish hotel industry. Scandinavian Journal of Management 19: 333-358. doi: 10.1016/S0956-5221(02)00034-9 
Chevalier JM, Buckles DJ (2008) SAS2: A guide to collaborative inquiry and social engagement. (Sage Publications). 305 pages.

Colfer CJP, Prabhu R, Günter M, McDougall C, Porro NM, Porro R (1999) Who counts most? Assessing human well-being in sustainable forest management. The Criteria and Indicators Toolbox Series 8. Center for International Forestry Research. Washington D.C., USA.

Cook D, Proctor W (2007) Assessing the threat of exotic plant pests. Ecological Economics 63: 594-604. doi: 10.1016/j.ecolecon.2006.12.021

Convention on Biological Diversity (1992) 31 ILM 818.

COP 10 (2010) Strategic plan for biodiversity. Adopted at the Conference of the Parties, Nagoya, Japan.

Davis MA, Chew MK, Hobbs RJ, Lugo AE, Ewel JJ, Vermeij GJ, Brown JH, Rosenzweig ML, Gardener MR, Carroll SP, Thompson K, Pickett STA, Stromberg JC, Del Tredici P, Suding KN, Ehrenfeld JG, Grime JP, Mascaro J, Briggs JC (2011) Don't judge species on their origin. Nature 474: 153-154. doi: 10.1038/474153a

De Lange WJ, Stafford WHL, Forsyth GG, Le Maitre DC (2012) Incorporating stakeholder preferences in the selection of technologies for using invasive alien plants as a bio-energy feedstock: Applying the analytical hierarchy process. Journal of Environmental Management 99: 76-83. doi: 10.1016/j.jenvman.2012.01.014

de Reynier YL, Levin PS, Shoji NL (2010) Bringing stakeholders, scientists, and managers together through an integrated ecosystem assessment process. Marine Policy 34: 534-540. doi: 10.1016/j.marpol.2009.10.010

de Wit MP, Crookes DJ, van Wilgen BW (2001) Conflicts of interest in environmental management: Estimating the costs and benefits of a tree invasion. Biological Invasions 3: 167178. doi: 10.1023/A:1014563702261

Essl F, Dullinger S, Rabitsch W, Hulme PE, Huelber K, JarošíkV, Kleinbauer I, Krausmann F, Kühn I, Nentwig W, Vilà M, Genovesi P, Gherardi F, Desprez-Loustau ML, Roques A, Pyšek P (2011) Socio-economic legacy yields an invasion debt. Proceedings of the National Academy of Sciences 108: 203-207. doi: 10.1073/pnas.1011728108

Forsyth GG, Le Maitre DC, O'Farrell PJ, van Wilgen BW (2012) The prioritisation of invasive alien plant control projects using a multi-criteria decision model informed by stakeholder input and spatial data. Journal of Environmental Management 103: 51-57. doi: 10.1016/j.jenvman.2012.01.034

Gardener M, Atkinson R, Rentería J (2010) Eradications and people: lessons from the plant eradication program in Galapagos. Restoration Ecology 18: 20-29. doi: 10.1111/j.1526100X.2009.00614.x

Goodenough A (2010) Are the ecological impacts of alien species misrepresented? A review of the "native good, alien bad" philosophy. Community Ecology 11: 13-21. doi: 10.1556/ ComEc.11.2010.1.3

Grafakos S, Flamos A, Oikonomou V, Zevgolis D (2010) Multi-criteria analysis weighting methodology to incorporate stakeholders' preferences in energy and climate policy interactions. International Journal of Energy Sector Management 4: 434-461. doi: $10.1108 / 17506221011073851$ 
Grimble R, Chan MK (1995) Stakeholder analysis for natural resource management in developing countries. Natural Resources Forum 19: 113-124. doi: 10.1111/j.1477-8947.1995.tb00599.x

Hare M, Pahl-Wostl C (2002) Stakeholder categorisation in participatory integrated assessment. Integrated Assessment 3: 50-62. doi: 10.1076/iaij.3.1.50.7408

Harris P (1988) Environmental impact of weed-control insects. BioScience 38: 542-548. doi: $10.2307 / 1310762$

Hopper LJ (2007) Landscape architectural graphic standards. Wiley. 576 pages.

Hulme PE (2012) Weed risk assessment: a way forward or a waste of time? Journal of Applied Ecology 49: 10-19. doi: 10.1111/j.1365-2664.2011.02069.x

Hurley MV, Lowell KE, Cook DC, Liu S, Siddique A-B, Diggle A (2010) Prioritizing biosecurity risks using a participatory decision-making tool. Human and Ecological Risk Assessment 16: 1379-1394. doi: 10.1080/10807039.2010.526506

Kapler EJ, Thompson JR, Widrlechner MP (2012) Assessing stakeholder perspectives on invasive plants to inform risk analysis. Invasive Plant Science and Management 5: 194-208. doi: 10.1614/IPSM-D-11-00067.1

Kowarik I, Bartz R, Heink U (2008) Bewertung «ökologischer Schäden» infolge des Anbaus gentechnisch veränderter Organismen (GVO) in der Landwirtschaft. Naturschutz und Biologische Vielfalt 56: 1-248.

Kueffer C, Hirsch Hadorn G (2008) How to achieve effectiveness in problem-oriented landscape research: The example of research on biotic invasions. Living Reviews in Landscape Research 2: 2. Stable URL: http://www.livingreviews.org/lrlr-2008-2

Kumschick S, Nentwig W (2010) Some alien birds have as severe an impact as the most effectual alien mammals in Europe. Biological Conservation 134: 2757-2762. doi: 10.1016/j. biocon.2010.07.023

Kumschick S, Alba C, Hufbauer RA, Nentwig W (2011) Weak or strong invaders? A comparison of impact between the native and invaded ranges of mammals and birds alien to Europe. Diversity and Distributions 17: 663-672. doi: 10.1111/j.1472-4642.2011.00775.x

Kumschick S, Bacher S, Blackburn TM (2012) What determines the impact of alien birds and mammals in Europe? Biological Invasions: in press. doi: 10.1007/s10530-012-0326-6

Lach D, List P, Steel B, Shindler B (2003) Advocacy and credibility of ecological scientists in resource decisionmaking: A regional study. BioScience 53(2): 170-178. Stable URL: http://www.ecologyandsociety.org/vol1/iss1/art9/

Lackey RT (2007) Science, scientists, and policy advocacy. Conservation Biology 21: 12-17. doi: $10.1111 /$ j.1523-1739.2006.00639.x

Lambdon P, Pyšek P, Basnou C, Arianoutsou M, Essl F, Hejda M, Jarošík V, Pergl J, Winter M, Anastasiu P, Andriopoulos P, Bazos I, Brundu G, Celesti-Grapow L, Chassot P, Delipetrou P, Josefsson M, Kark S, Klotz S, Kokkoris Y, Kühn I, Marchante H, Perglová I, Pino J, Vilà M, Zikos A, Roy D, Hulme P (2008) Alien flora of Europe: species diversity, temporal trends, geographical patterns and research needs. Preslia 80: 101-149. URL: http://www.ibot.cas.cz/preslia/P082Lam.pdf

Leung B, Roura-Pascual N, Bacher S, Heikkilä J, Brotons L, Burgman MA, Dehnen-Schmutz K, Essl F, Hulme PE, Richardson DM, Sol D, Vilà M (2012) Assessment of risk assessments of invasive alien species. Ecology Letters 15: 1475-1493. doi: 10.1111/ele.12003 
Liu S, W Proctor, Cook D (2010) Using an integrated fuzzy set and deliberative multi-criteria evaluation approach to facilitate decision-making in invasive species management. Ecological Economics 69: 2374-2382. doi: 10.1016/j.ecolecon.2010.07.004

Liu S, Sheppard A, Kriticos D, Cook D (2011) Incorporating uncertainty and social values in managing invasive alien species: a deliberative multi-criteria evaluation approach. Biological Invasions 13: 2323-2337. doi: 10.1007/s10530-011-0045-4

Liu S, Walshe T, Long G, Cook D (2012) Evaluation of potential responses to invasive nonnative species with structured decision making. Conservation Biology 26: 539-546. doi: 10.1111/j.1523-1739.2012.01843.x

Maguire LA (2004) What can decision analysis do for invasive species management? Risk Analysis 24: 859-868. doi: 10.1111/j.0272-4332.2004.00484.x

Mark M, Shotland L (1985) Stakeholder-based evaluation and value judgements. Evaluation Review 9(5): 605-626. doi: 10.1177/0193841X8500900504

Marris E (2006) Should conservation biologists push policies? Nature 442: 13. doi: $10.1038 / 442013 \mathrm{a}$

Mitchell RK, Agle BR, Wood DJ (1997) Toward a theory of stakeholder identification and salience: defining the principle of who and what really counts. Academy of Management Review 22: 853-886. URL: http://www.jstor.org/stable/259247

Mushove P, Vogel C (2005) Heads or tails? Stakeholder analysis as a tool for conservation area management. Global Environmental Change 15: 184-198. doi: 10.1016/j.gloenvcha.2004.12.008

Myers JH, Simberloff D, Kuris AM, Carey JR (2000) Eradication revisited: dealing with exotic species. Trends in Ecology \& Evolution 15: 316-320. doi: 10.1016/S01695347(00)01914-5

Nentwig W, Kühnel E, Bacher S (2010) A generic impact-scoring system applied to alien mammals in Europe. Conservation Biology 24: 302-311. doi: 10.1111/j.15231739.2009.01289.x

O’Dowd DJ, Green PT, Lake PS (2003) Invasional meltdown on an oceanic island. Ecology Letters 6: 812-817. doi: 10.1046/j.1461-0248.2003.00512.x

Ou J, Lu C, O’Toole DK (2008) A risk assessment system for alien plant bio-invasion in Xiamen, China. Journal of Environmental Sciences 20: 989-997. doi: 10.1016/S10010742(08)62198-1

Parker IM, Simberloff D, Lonsdale WM, Goodell K, Wonham M, Kareiva PM, Williamson MH, Von Holle B, Moyle PB, Byers JE, Goldwasser L (1999) Impact: toward a framework for understanding the ecological effects of invaders. Biological Invasions 1: 3-19. doi: 10.1023/A:1010034312781

Perrings C, Fenichel E, Kinzig A (2010) Globalization and invasive alien species: trade, pests, and pathogens. In Perrings C, Mooney HA, Williamson M (Eds.) Bioinvasions and globalization: ecology, economics, management and policy. Oxford University Press (New York): 42-55.

Pheloung PC, Williams PA, Halloy SR (1999) A weed risk assessment model for use as a biosecurity tool evaluating plant introductions. Journal of Environmental Management 57: 239-252. doi: 10.1006/jema.1999.0297 
Pimentel D, Zuniga R, Morrison D (2005) Update on the environmental and economic costs associated with alien-invasive species in the United States. Ecological Economics 52: 273288. doi: 10.1016/j.ecolecon.2004.10.002

Pluess T (2011) Enhancement of pest risk analysis techniques. PhD dissertation no. 1708, University of Fribourg, Switzerland.

Pluess T, Cannon R, Jarošík V, Pergl J, Pyšek P, Bacher S (2012a) When are eradication campaigns successful? A test of common assumptions. Biological Invasions 14: 1365-1378. doi: 10.1007/s10530-011-0160-2

Pluess T, Jarošík V, Pyšek P, Cannon R, Pergl J, Breukers A, Bacher S (2012b) Which factors affect the success or failure of eradication campaigns against alien species? PLoSOne, 7(10): e48157. doi: 10.1371/journal.pone.0048157

Pretty JN (1995) Participatory learning for sustainable agriculture. World Development 23: 1247-1263. doi: 10.1016/0305-750X(95)00046-F

Pyšek P, Lambdon PW, Arianoutsou M, Kühn I, Pino J, Winter M (2009) Aliens vascular plants of Europe. In DAISIE (Eds.) The handbook of alien species in Europe. Springer (Dordrecht): 43-61.

Pyšek P, Jarosik V, Hulme PE, Pergl J, Hejda M, Schaffner U, Vilà M (2012) A global assessment of invasive plant impacts on resident species, communities and ecosystems: the interaction of impact measures, invasive species' traits and environment. Global Change Biology 19: 1725-1737. doi: 10.1111/j.1365-2486.2011.02636.x

Randall JM, Morse LE, Benton N, Hiebert R, Lu S, Killeffer T (2008) The invasive species assessment protocol: A tool for creating regional and national lists of invasive nonnative plants that negatively impact biodiversity. Invasive Plant Science and Management 1: 3649. doi: 10.1614/IPSM-07-0201

Reaser JK, Meyerson LA, Cronk Q, De Poorter M, Eldrege LG, Green E, Kairo M, Latasi P, Mack RN, Mauremootoo J, O’Dowd D, Orapa W, Sastroutomo S, Saunders A, Shine C, Thrainsson S, Vaiutu L (2007) Ecological and socioeconomic impacts of invasive alien species in island ecosystems. Environmental Conservation 34: 98-111. doi: 10.1017/ S0376892907003815

Reed MS (2008) Stakeholder participation for environmental management: a literature review. Biological Conservation 141: 2417-2431. doi: 10.1016/j.biocon.2008.07.014

Reed MS, Graves A, Dandy N, Posthumus H, Hubacek K, Morris J, Prell C, Quinn CH, Stringer LC (2010) Who's in and why? A typology of stakeholder analysis methods for natural resource management. Biological Conservation 143: 2956-2964. doi: 10.1016/j. jenvman.2009.01.001

Renn O, Schweizer P-J (2009) Inclusive risk governance: concepts and application to environmental policy making. Environmental Policy and Governance 19: 174-185. doi: 10.1002/eet.507 Robertson M, Villet M, Fairbanks D, Henderson L, Higgins S, Hoffmann J, Le Maitre D, Palmer A, Riggs I, Shackleton C, Zimmermann HG (2003) Proposed prioritization system for the management of invasive alien plants in South Africa. South African Journal of Science 99: 37-43.

Roura-Pascual N, Krug RM, Richardson DM, Hui C (2010) Spatially-explicit sensitivity analysis for conservation management: exploring the influence of decisions in invasive al- 
ien plant management. Diversity and Distributions 16: 426-438. doi: 10.1111/j.14724642.2010.00659.x

Rowe G, Frewer LJ (2005) A typology of public engagement mechanisms. Science, Technology \& Human Values 30: 251-290. doi: 10.1177/0162243904271724

Sagoff M (2011) The quantification and valuation of ecosystem services. Ecological Economics 70: 497-502. doi: 10.1016/j.ecolecon.2010.10.006

Schlaepfer MA, Sax DF, Olden DO (2011) The potential conservation value of non-native species. Conservation Biology 25(3): 428-437. doi: 10.1111/j.1523-1739.2010.01646.x

Scott JM, Rachlow JL, Lackey RT, Pidgorna AB, Aycrigg JL, Feldman GR, Svancara LK, Rupp DA, Stanish DI (2007) Policy advocacy in science: prevalence, perspectives, and implications for conservation biologists. Conservation Biology 21: 29-35. doi: 10.1111/j.15231739.2006.00641.x

Simberloff D, Martin JL, Genovesi P, Maris V, Wardle DA, Aronson J, Courchamp F, Galil B, García-Berthou E, Pascal M, Pyšek P, Sousa R, Tabacchi E, Vilà M (2012) Impacts of biological invasions: what's what and the way forward. Trends in Ecology and Evolution: in press. doi: 10.1016/j.tree.2012.07.013

Skinner K, Smith L, Rice P (2000) Using noxious weed lists to prioritize targets for developing weed management strategies. Weed Science 48: 640-644. doi: 10.1614/0043-1745(2000)048[0640:UNWLTP]2.0.CO;2

Skurka Darin GM, Schoenig S, Barney JN, Panetta FD, DiTomaso JM (2011) WHIPPET: A novel tool for prioritizing invasive plant populations for regional eradication. Journal of Environmental Management 92: 131-139. doi: 10.1016/j.jenvman.2010.08.013

Stoll-Kleemann S, Welp M (2006) Stakeholder dialogues in natural resources management: theory and practice. Springer (Berlin/Heidelberg). 386 pages. doi: 10.1007/978-3-540-36917-2

Tassin J, Rivière J-N, Cazanove M, Bruzzese E (2006) Ranking of invasive woody plant species for management on Rè Island. Weed Research 46: 388-403. doi: 10.1111/j.13653180.2006.00522.x

Taut S (2007) Studying self-evaluation capacity building in a large international development organization. American Journal of Evaluation 28(1): 45-59. doi: $10.1177 / 1098214006296430$

Unruh D (2005) Using primary and secondary stakeholders to define facility-to-community transition needs for adjudicated youth with disabilities. Evaluation and Program Planning 28: 413-422. doi: 10.1016/j.evalprogplan.2005.07.005

Vilà M, Basnou C, Pyšek P, Josefsson M, Genovesi P, Gollasch S, Nentwig W, Olenin S, Roques A, Roy D, Hulme PE, DAISIE Partners (2010) How well do we understand the impacts of alien species on ecosystem services? A pan-European, cross-taxa assessment. Frontiers in Ecology and the Environment 8: 135-144. doi: 10.1890/080083

Virtue JG, Groves RH, Panetta FD (2001) Towards a system to determine the national significance of weeds in Australia. In Groves RH, Panetta FD, Virtue JG (Eds.) Weed Risk Assessment. CSIRO Publishing (Collingwood, Australia): 124-152.

Weber J, Panetta FD, Virtue J, Pheloung P (2009) An analysis of assessment outcomes from eight years' operation of the Australian border weed risk assessment system. Journal of Environmental Management 90: 798-807. doi: 10.1016/j.jenvman.2008.01.012 
Webler T, Tuler S (2006) Four perspectives on public participation process in environmental assessment and decision making: combined results from 10 case studies. The Policy Studies Journal 34: 699-722. doi: 10.1111/j.1541-0072.2006.00198.x

Wesselink A, Paavola J, Fritsch O, Renn O (2011) Rationales for public participation in environmental policy and governance: practitioners' perspectives. Environment and Planning A 43: 2688-2704. doi: 10.1068/a44161

Wilhere GF (2008) The how-much-is-enough myth. Conservation Biology 22: 514-517. doi: 10.1111/j.1523-1739.2008.00926.x

Wilhere GF, Maguire LA, Scott JM, Rachlow JL, Goble DD, Svancara LK (2012) Conflation of values and science: Response to Noss et al.. Conservation Biology 26: 943-944. doi: 10.1111/j.1523-1739.2012.01900.x

\section{Appendix A}

Definitions of change assessment (impact) scores for IAS. Effects were divided into two main classes with six categories each.

\section{Environmental impact}

\subsubsection{Herbivory/toxicity negative}

0 No impact known or detectable.

1 Very low level of herbivory (animals) or toxicity (plants or animals) on at least one native species, no major damage reported.

2 Herbivory or toxicity affecting several native species, without large impact on affected species or decline of their populations.

3 Herbivory or toxicity affecting several native species, at least one native species declining.

4 Herbivory or toxicity affecting many native species, several declining in population size, recorded community change reversible.

5 Herbivory or toxicity affecting native species listed as vulnerable, endangered or critically endangered by IUCN, decline of these species, replacement or even extinction of species, recorded community change irreversible.

\subsubsection{Herbivory/toxicity positive}

0 No impact known or detectable.

+1 Very low level of herbivory or toxicity affecting at least one species degrading the ecosystem, no impact on performance of affected species recorded.

+2 Herbivory or toxicity affecting one or several species degrading the ecosystem, without large impact on affected species or decline of their populations.

+3 Herbivory or toxicity affecting one or several species degrading the ecosystem, at least one species declining, some/first indications that the ecosystem changes towards its historical functional state. 
+4 Herbivory or toxicity affecting one to many species degrading the ecosystem, declining in population size, strong indications that the ecosystem changes towards its historical functional state.

+5 Complete re-establishment of functional state of historical ecosystem that was degraded before invasion of alien species.

\subsubsection{Competition negative}

0 No impact known or detectable.

1 For animals, very low level of competition with at least one native species, exploitation competition; for plants, low abundance, native species richness not declining.

2 For animals, competition with several native species by exploitation competition, without large impact on affected species or decline of their populations; for plants, moderate abundance, decrease in native species abundance but not richness.

3 For animals, competition with several species, interference competition, at least one native species declining; for plants, high abundance, decrease in native abundance, at least one native species lost.

4 For animals, competition with many native species, several declining in population size, competition for food and/or space, behavioural changes in out-competed species; for plants, high abundance, strong decline in both abundance and richness of native species, native species still able to recruit.

5 For animals, competes with species listed as vulnerable, endangered or critically endangered by IUCN, decline of these species, replacement or even extinction of species; for plants, mono-dominant/near mono-dominant, with no or very few native species remaining; limiting native species recruitment options.

\subsubsection{Competition positive}

0 No impact known or detectable.

+1 For animals, very low level of competition with at least one native species degrading the ecosystem, exploitation competition, no impact on performance of affected species recorded; for plants, no loss in abundance or richness of native species.

+2 For animals, competition with one or several native species degrading the ecosystem by exploitation competition, without large impact on affected species or decline of their populations; for plants, small increase in abundance of native species, no increase in species richness.

+3 For animals, competition with one or several species degrading the ecosystem, interference competition, at least one species declining, some indications that the ecosystem changes towards its historical functional state; for plants, increase in abundance of native species, small increase in species diversity. 
+4 For animals, competition with one to many species degrading the ecosystem, declining in population size, strong indications that the ecosystem changes towards its historical functional state; for plants, increase in abundance of native species and in species diversity.

+5 For animals, completely re-establish functional state of historical ecosystem that was degraded before invasion of alien species; for plants, increase in abundance of native species and in species diversity, including threatened native species.

\subsubsection{Predation negative (not relevant for plants)}

0 No impact known or detectable.

1 Predation known but negligible, no decline of native species.

2 Predation on several abundant species, without large impact on affected species or decline of their populations.

3 Decline of one to several native species recognized, minor change in food web structure reported.

4 Decline of many species, indirect impact by mesopredator release, clear changes in the food web.

5 Preys also on endemic or species listed as vulnerable, endangered or critically endangered by IUCN, local extinction.

\subsubsection{Predation positive (not relevant for plants)}

0 No impact known or detectable.

+1 Predation on species degrading the ecosystem known but negligible, no decline of species.

+2 Predation on one or several species degrading the ecosystem, without large impact on affected species or decline of their populations.

+3 Decline of one to several native species degrading the ecosystem recognized, minor change in food web structure reported, some indications that the ecosystem changes towards its historical functional state.

+4 Decline of one to many species degrading the ecosystem, clear changes in the food web, strong indications that the ecosystem changes towards its historical functional state.

+5 Completely re-establish functional state of historical ecosystem that was degraded before invasion of alien species.

\subsubsection{Transmission of diseases to wildlife negative}

0 No impact known or detectable.

1 Host (plant or animal) for non-specific parasites, occasional transmission of more or less harmless diseases to one native species. No population decline in native species. If a plant, species is not a breeding ground for wildlife disease vectors. 
2 Occasional transmission of more or less harmless diseases, several native species affected. No or only minor population decline in native species. If a plant, species may be a breeding ground for wildlife disease vectors, but no more so than native plant species.

3 Many native species affected, frequent transmission of more or less harmless diseases or harmful diseases transmitted to one native species. Minor population decline in native species. If a plant, may be a more significant breeding ground for wildlife disease vectors than native plant species.

4 Transmits harmful diseases to several native species or more or less harmless diseases to endemic or species listed as vulnerable, endangered or critically endangered by IUCN. Moderate population decline in native species. If a plant, a major breeding ground for wildlife disease vectors, outbreaks due to species presence uncertain.

5 Transmits harmful diseases to many species and/or species listed as vulnerable, endangered or critically endangered by IUCN by direct transmission, decline of these species or extinction. If a plant, a major breeding ground for wildlife disease, outbreaks due to species presence certain.

\subsubsection{Transmission of diseases to wildlife positive}

0 No impact known or detectable.

+1 Occasional transmission of more or less harmless diseases to one species degrading the ecosystem; no population decline in species. Potential positive effect on health of wildlife (direct: e.g. potential medicinal species; indirect: e.g. antagonist of a health threat), but not yet reported.

+2 Occasional transmission of more or less harmless diseases, one or several species degrading the ecosystem affected. No or only minor population decline in species. Occasional, small positive effect on health of wildlife.

+3 One to many species degrading the ecosystem affected, frequent transmission of more or less harmless diseases or harmful diseases transmitted to one species degrading the ecosystem. Minor population decline in species, some indications that the ecosystem changes towards its historical functional state. Regularly small positive effect on health of wildlife, or occasional, larger positive effect on health of wildlife.

+4 Transmits harmful diseases to one to several species degrading the ecosystem. Moderate population decline in species, strong indications that the ecosystem changes towards its historical functional state. Regularly leading to larger positive effect on health of wildlife.

+5 Completely re-establish functional state of historical ecosystem that was degraded before invasion of alien species. Massive positive effect on health of wildlife caused by species. 


\subsubsection{Hybridization negative}

0 No impact known or detectable.

1 Hybridization possible in captivity, but only rarely in the wild.

2 Hybridization is more common in the wild, no offspring, but constraints to normal mating.

3 Hybridization is more common, with offspring, but not fertile.

4 Hybridization common with fertile offspring.

5 Risk of extinction of endangered species.

\subsubsection{Hybridization positive}

0 No impact known or detectable.

+1 Hybrids are capable of coping with degraded ecosystem process(es), e.g. shown in laboratory experiments, but no indications are found in the field.

+2 Hybrids are able to cope with degraded ecosystem process(es) in the field.

+3 Some/first indications that hybrid changes the ecosystem towards its historical functional state.

+4 Strong indications that hybrid changes the ecosystem towards its historical functional state.

+5 Completely re-establish functional state of historical ecosystem that was degraded before invasion of the hybrid species.

\subsubsection{Impact on ecosystem (other than mentioned before, i.e. chemical, physi- cal or structural changes) negative}

0 No impact known or detectable.

1 Change in chemical (e.g. eutrophication, nutrient-cycling), physical (e.g. soil compaction, structure, hydrology) and/or structural (e.g. felled trees, burrows, disturbance dynamics) characteristics detectable, but no impact on performance of natives or successional processes.

2 Moderate change in chemical, physical and/or structural characteristics, only slight impact on performance of natives or successional processes.

3 Major change in chemical, physical and/or structural characteristics, change in fauna and flora and/or successional processes, reversible.

4 Severe changes in chemical, physical and/or structural characteristics, decline of species and/or change in species composition, strong impact on successional processes, but likely to be reversible.

5 Massive changes in chemical, physical and/or structural characteristics, endemic species and/or species listed as vulnerable, endangered or critically endangered by IUCN affected, decline of species and/or change in species composition, very strong impact on successional processes, loss of habitat characteristics, damage of sites of conservation importance, irreversible. 


\subsubsection{Impact on ecosystem positive}

0 No impact known or detectable.

+1 Change towards historical state of the ecosystem in chemical (e.g. eutrophication, nutrient-cycling), physical (e.g. soil compaction, structure, hydrology) or structural (e.g. felled trees, burrows, disturbance dynamics) characteristics detectable, but no decline of populations of species responsible for the ecosystem degradation or successional processes.

+2 Moderate change towards historical state of the ecosystem in chemical, physical or structural characteristics, only slight decline of populations of species responsible for the ecosystem degradation or successional processes.

+3 Major change towards historical state of the ecosystem in chemical, physical or structural characteristics, decline of populations of species responsible for the ecosystem degradation, major change towards historical state of the ecosystem in fauna and flora or successional processes.

+4 Severe changes in chemical, physical or structural characteristics, major decline of species responsible for the ecosystem degradation or severe change towards historical state of the ecosystem in species composition or successional processes.

+5 Complete change towards historical state of the ecosystem in chemical, physical or structural characteristics, removal of species responsible for the ecosystem degradation, re-establishment of historical habitat characteristics and successional processes.

\section{Socio-economic impact}

\subsubsection{On agriculture negative}

0 No impact known or detectable.

1 Only occasional damage or yield loss to crops or plantations (e.g. orchards), damage similar to native species; for plants, plant present, but no operational obstruction or removal/control cost.

2 Damage or yield loss to crops common, damage or yield loss similar to native species; for plants, little operational obstruction or removal/control cost. Some trade disruptions.

3 Regular damage or yield loss similar to native species through feeding on crops or through competition, occasional threat to stored food, losses exceed impact of the native fauna and flora, sometimes reaching high levels; for plants, operational obstruction and costs to remove/manage invader are still minor. Moderate trade disruptions.

4 Regular high damage or yield loss in fields or to stored food, fruit consumption; for plants, operational obstruction and costs to remove/manage invader are considerable. High trade disruptions.

5 Complete loss of yield or destruction of fields or plantations (e.g. orchards), or of stored food by consumption and contamination; for plants, operational obstruction and costs to remove/manage invader prohibit profitable agriculture on invaded land. Massive trade disruptions. 


\subsubsection{On agriculture positive}

0 No impact known or detectable.

+1 Biological traits and life-style suggest potential positive influence on the yield or quality, but not yet reported.

+2 Occasionally leading to additional yield or increased quality, yield or quality increase small.

+3 Regularly leading to small yield or quality increase or occasionally to larger yield or quality increase.

+4 Regularly leading to larger yield or quality increase.

+5 Massive yield or quality gain caused by species.

\subsubsection{On animal production negative}

0 No impact known or detectable.

1 Occasional competition with, or loss of yield in livestock or animal production. Plant present but no operational obstruction or removal/control cost.

2 Competition with, or loss of yield in livestock or animal production, transmission of diseases to livestock or production animals in the native area, but not yet reported from the area of introduction. Little operational obstruction or removal/control cost. Some trade disruptions.

3 Competition more frequent with several livestock or production animal species, transmission of diseases reported, but infection rates low. Pollution by droppings on farmland which domestic stock are then reluctant to graze; for plants, loss of yield in livestock or production animals common, operational obstruction or removal/control cost minor. Plant may be toxic to livestock or production animals. Moderate trade disruptions.

4 For animals, transmission of economically important diseases or hybridization with economically important game animals; for plants, loss of yield in livestock or production animals major, operational obstruction or removal/control cost considerable. Plant toxic to livestock or production animals, fatalities uncommon. Large trade disruptions.

5 For animals, transmission of harmful diseases to or hybridization with livestock or production animals; for plants, loss of yield in livestock or production animals major, operational obstruction or removal/control costs are prohibitive. Plant highly toxic to livestock or production animals, fatalities reported. Massive trade disruptions.

\subsubsection{On animal production positive}

0 No impact known or detectable.

+1 Biological traits and life-style suggest potential positive influence on animal production (e.g. direct: potential livestock or game species, fur production; indirect: e.g. fodder plant, (micro-)organisms increasing yield or quality of fodder plants), but not yet reported. 
+2 Occasionally leading to increased production or quality, production increase small.

+3 Regularly leading to small production or quality increase or occasionally to larger production or quality increase.

+4 Regularly leading to larger production or quality increase.

+5 Massive production or quality gain caused by species.

\subsubsection{On forestry negative}

0 No impact known or detectable.

1 For animals, minor impact through herbivory; for plants, little or no loss of yield or quality or operational obstruction, no change to forest structure or regeneration.

2 For animals, impact through herbivory, minor effect on forest growth, impact on seed dispersal; for plants, minor loss of yield or quality, or operational obstructions, minor changes to forest structure, minor reduction in regeneration. Some trade disruptions.

3 For animals, constrains forest regeneration through browsing on young trees, damage to plantations, gnawing of bark, damage by causing floods; for plants, moderate loss of yield or quality, changes in forest structure, impeded regeneration. Moderate trade disruptions.

4 For animals; moderate to strong damage to mature forest through seed consumption, bark stripping or antler rubbing, death of trees by felling or flooding. Killing trees by defoliating them for nesting material; for plants, strong loss of yield or quality, decline in desired canopy tree species, decline in regeneration potential, major changes to forest structure. Large trade disruptions.

5 For animals; very strong damage to mature forest through seed consumption, bark stripping or antler rubbing, death of trees by felling or flooding; for plants, very strong loss of yield or quality, complete loss or replacement of desired canopy tree species, no regeneration, complete change in forest structure. Massive trade disruptions.

\subsubsection{On forestry positive}

0 No impact known or detectable.

+1 Biological traits and life-style suggest potential positive influence on forest production (e.g. direct: potential forestry species; indirect: e.g. (micro-)organisms increasing yield or quality of forestry plants), but not yet reported.

+2 Occasionally leading to increased forestry production or quality, compared to native species, production or quality increase small.

+3 Regularly leading to small forestry production or quality increase, compared to native species, or occasionally to larger production or quality increase.

+4 Regularly leading to larger forestry production or quality increase, compared to native species.

+5 Massive forestry production or quality gain, compared to native species, caused by species. 


\subsubsection{On infrastructure negative}

0 No impact known or detectable.

1 Biological traits and life-style suggest potential damage to infrastructure (e.g. potential to increase soil erosion and decrease road stability, physical damage to property and infrastructure, disruption to transport and communications) but not yet reported.

2 Occasional damage with minor economic losses, e.g. damage to fences, impact through pollution, accumulations of droppings, minor increases in soil erosion, localized damage to buildings and ground surfaces from roots and rhizomes (for plants), rare infrastructure problems (clogging up waterways, festooning power lines for plants),

3 Damage to fences and/or plantations, gnawing electricity cables etc., causing road accidents, nesting on current conductions. Moderate increase in soil erosion, moderate damage to property, buildings and infrastructure, frequent obstruction of waterways.

4 Considerable damage to property and infrastructure, with considerable economic costs, damage through burrowing or nesting in buildings, or roots and rhizomes of plants. Major obstruction of waterways.

5 Considerable damage to flood defence systems or other critical infrastructure, major soil erosion, danger to human safety, threat to transport safety.

\subsubsection{On infrastructure positive}

0 No impact known or detectable.

+1 Have traits or attributes likely to help preserve infrastructure, but not yet reported.

+2 Minor ability to preserve and enhance infrastructure, but performance no better than native or non-plant alternatives. No economic gain.

+3 Moderate ability to preserve and enhance infrastructure (prevent soil erosion), better than non-plant alternative. Marginal economic gain.

+4 Strong ability to preserve and enhance infrastructure better than nonplant alternative, e.g. flood defence and soil preservation, prevention of landslides. Moderate economic gain.

+5 Best option for preserving and enhancing infrastructure, better than nonplant alternative, high economic gain, preserves human safety.

\subsubsection{On human health negative}

0 No impact known or detectable.

1 Host of one or more harmless diseases with the possibility of infecting humans, not yet reported; for plants, known to be mildly toxic, causing mild discomfort, no cases yet reported.

2 Host of several harmless diseases, indirect transmission or possibility of direct transmission, but only a small percentage of the human population at risk, health hazard from soil and water contamination caused by drop- 
pings; for plants, mildly toxic or causing mild discomfort, exposure risk low (not easily ingested, not airborne, direct contact causes no reaction), few cases reported.

3 Direct infection with one or more harmless diseases, occasional health threat through bites or other attacks; for plants, toxic, and/or causing pain, injury or discomfort, exposure risk moderate (poisoning through ingestion, airborne, direct contact causes reaction), moderate number of cases reported.

4 Direct transmission of several diseases, infection by contaminated food common, host of harmful diseases in the native range, but not yet known from the invaded range. Health threat through bites or other injuries happen more often, rarely fatal. Plants highly toxic, and/or causing strong pain/discomfort, but rarely fatal - many cases reported. Exposure risk high, through ingestion, contamination, direct contact, airborne.

5 Vector of harmful diseases to humans and/or many diseases frequently transmitted. Health threat through bites or other injuries happen frequently, more often fatal. Plants highly toxic, causing severe pain and/ or discomfort, fatalities reported, or severe disruption to daily life caused through effects on human health. High risk of exposure.

\subsubsection{On human health positive}

0 No impact known or detectable.

+1 Biological traits and life-style suggest potential positive effect on human health (direct: e.g. potential medicinal species; indirect: e.g. antagonist of a health threat, ameliorating human living conditions), but not yet reported.

+2 Occasional, small positive effect on human health.

+3 Regularly small positive effect on human health, or occasional, larger positive effect on human health.

+4 Regularly leading to larger positive effect on human health.

+5 Massive positive effect on human health caused by species.

\subsubsection{On human social life negative}

0 No impact known or detectable.

1 Biological traits and life-style suggest potential for disturbance in recreational or residence areas (e.g. by noise, pollution, overgrowing), but nothing yet reported.

2 Occasional small disturbance, only small percentage of human population affected.

3 Regular small disturbance, or occasional larger disturbance.

4 Regular larger disturbance. Recreational value of a habitat or a landscape strongly affected.

5 Massive disturbance; complete loss of recreational value of a habitat or a landscape. 


\subsubsection{On human social life positive}

0 No impact known or detectable.

+1 Biological traits and life-style suggest potential positive effect for recreational or residence areas (e.g. charismatic or decorative species, species ameliorating the environment by providing e.g. shade, or having edible parts, or species potentially used for angling or hunting), but not reported so far.

+2 Occasional small positive effect for recreational or residence areas, only small percentage of human population affected.

+3 Regular small positive effect for recreational or residence areas, or occasional larger positive effect for recreational or residence areas.

+4 Regular larger positive effect for recreational or residence areas. Recreational value of a habitat or a landscape strongly increased.

+5 Massive positive effect for recreational or residence areas. Massive gain of recreational value of a habitat or a landscape. 